\title{
The relationship between eudaimonic wellbeing, emotional intelligence and affect in early adolescents
}

\author{
Carlos Salavera $^{1,2}$ (1) Pablo Usán ${ }^{1,2}$ \\ Accepted: 17 November 2020 \\ (C) Springer Science+Business Media, LLC, part of Springer Nature 2020
}

\begin{abstract}
This study aims to analyse the relationship between eudaimonic well-being, emotional intelligence and affects in early adolescents. Eudaimonic well-being is based on the development of personal skills, based on the premise that people are happy if they have a life purpose, challenges and growth. Emotional intelligence and affects can play a key role in this. The sample analysed comprised 344 first- and second-year secondary school students, aged 12 to 15 years ( $49.13 \%$ boys; $\mathrm{M}$ age $=12.86$ years), and the relationship between the three target constructs - eudaimonic well-being, affects and emotional intelligence - was analysed. The survey was designed as a lateral study based on natural groups. The instruments used were the Eudaimonic well-being questionnaire, the Emotional intelligence questionnaire and the Positive and negative affect scale for children and adolescents. The results show that these constructs are related to one another. One in three participants yielded low scores in terms of eudaimonic well-being, emotional intelligence and positive affects. One in three yielded high values. The study also analysed the mediating role that emotional intelligence plays in well-being, which is increased when affects play a mediating role. According to our research, the emotional intelligence has a direct positive effect on well-being of $0.31(p<0.001)$, with a total effect (direct + indirect effects) mediated by positive and negative affects of $0.48(p<0.001)$, which suggests that positive and negative affects directly mediate the relationship between EI and eudaimonic well-being. Regression analysis revealed that three of the components of emotional intelligence (emotional self-awareness, emotional regulation and the use of emotions in problemsolving) and positive and negative affects can be used to predict eudaimonic well-being, with an aggregate variance of $70.2 \%$. It is concluded that emotional intelligence and affects play a role in eudaimonic well-being in early adolescents. Therefore, early emotional and affective training can lead to an increase in eudaimonic well-being, which opens interesting avenues for future research.
\end{abstract}

Keywords Eudaimonic well-being $\cdot$ Emotional intelligence $\cdot$ Affects $\cdot$ Early adolescents

Well-being and positive psychology are an important focus for many educational professionals. The ability of this approach to improve people's psychological health is now beyond question (Seligman \& Csikszentmihalyi, 2000). Positive psychology maintains that health goes beyond the absence of disease and seeks to identify the factors that contribute to the well-being of adolescents, as well as to improve their academic performance.

Carlos Salavera

salavera@unizar.es

1 Investigation Research Group OPIICS, Universidad de Zaragoza, Zaragoza, Spain

2 Facultad de Educación, Universidad de Zaragoza, c/ Pedro Cerbuna, 12, 50009 Zaragoza, Spain
An important factor of well-being is subjective well-being, which has traditionally been explained from two perspectives: hedonic and eudaimonic (Cooke, Melchert, \& Connor, 2016; Church et al., 2014; Huta \& Waterman, 2014). The hedonic perspective refers to that which provides or is related to pleasure, and is linked to the subjective experience of pleasure regardless of its source. From this perspective, subjective well-being is thought to reflect a variety of subjective evaluations about quality of life in the broadest sense (Kahneman, Diener, \& Schwarz, 1999). The hedonic approach considers the importance of engaging in activities that create positive emotional experiences, lack of negative feelings and general satisfaction with life (Diener, Lucas, \& Oishi, 2018).

On the other hand, the eudaimonic approach focuses on the factors that promote personal growth and the realization of human potential. This eudaimonic perspective regards subjective well-being as a long-term positive psychological state 
which results from the individual's commitment to different development and existential life challenges, the meaning of life and self-reflection, excluding the affective component (Besser, 2016; Ryan \& Deci, 2001; Waterman, 1993).

It can be said that hedonia stems from meeting one's desires, while eudaimonia is part of one's desires; Waterman (2011) argues that eudaimonia cannot be achieved in the absence of hedonia. However, although hedonia- and eudaimonia-related values are strongly correlated, some differences can be attested (Huta \& Waterman, 2014). Hedonic activities tend to disregard personal problems, and are related with relaxation, content, emotion and happiness. Eudaimonic activities require great effort and are associated with personal development; they are characterised by a balance between challenges and skill, and pursue well-defined targets. It has been argued that it is preferable to work on eudaimonia (Waterman, 2008), as this presents the opportunity for developing personal potential from a philosophical perspective that focus on self-realisation.

\section{Affects and Eudaimonic Well-Being}

Affects are generally related to hedonia, and some even refer to them as affective well-being (Diener et al., 2018). They are regarded as an important part of hedonia, insofar as they are related to activities that generate positive emotional experiences. However, since the eudaimonic approach is related to meaning and self-realisation, well-being being considered the full measure of personal performance (Ryan \& Deci, 2001) in terms of resources, strengths, meaning of life, authenticity and purpose (Waterman et al., 2010), this study aims to analyse the mediating role of affects in eudaimonic well being from both a eudaimonic and a hedonic perspective (Di Fabio \& Saklofske, 2018).

\section{Emotional Intelligence and Eudaimonic Well-Being}

Emotional intelligence (EI) is generally referred to as the individual's knowledge and skill to efficiently face emotions and regulate his or her social and emotional behaviour (Cabello \& Fernández-Berrocal, 2015; Mayer, Caruso, \& Salovey, 2016; Petrides, 2016). Emotions affect people's thoughts in the same way their cognitive processes affect their emotional states (Tamir, Vishkin, \& Gutentag, 2020; Zhoc, Li, \& Webster, 2016). As such, they are not contradictory, but complementary aspects (Karaś \& Cieciuch, 2018; Mayer, Salovey, Caruso, \& Cherkasskiy, 2011).

Recent debates have framed the study of EI within two conceptual approaches. The first frames EI as a skill concerning the emotional processing of information and the skills related to this processing. In this regard, EI is defined as the individual ability to perceive feelings in a precise and correct way, the ability to assimilate and understand them, and the ability to regulate and modulate one's own and others' emotional states (Fernández-Berrocal \& Extremera, 2005; Mayer, Salovey, \& Caruso, 2008). The second framework, also known as mixed or traits models, includes EI as a stable behavioural and personality feature, that is, a behavioural disposition that is best measure by self-report (Petrides, 2016).

From the perspective that relates EI to eudaimonic wellbeing, EI should contribute to positive affects with others and to creating an environment conducive to personal development, positive meaning of life and realisation (Bhullar, Schutte, \& Malouff, 2013; Canero, Monaco, \& Montoya, 2019; Di Fabio \& Kenny, 2016; Sánchez-Álvarez, Extremera, \& Fernández-Berrocal, 2016; Zeidner, Matthews, \& Roberts, 2012).

\section{The Present Study}

Cross-sectional associations among eudaimonic well-being, emotional intelligence and affects have been reported. However, comprehensive analyses of the relationships among eudaimonic well-being, EI and affects are still lacking. Similarly, none of the existing studies focus on adolescent population groups. According to the above theoretical background, the aim of this study was to assess the relationship between eudaimonic well-being, emotional intelligence and affects in early adolescents, through the use of three questionnaires, one for each of the constructs under consideration. According to the theoretical framework outlined above, eudaimonic well-being, which is related to the potential for personal development (Waterman, 2008, 2011) is expected to be related with affects and EI.

\section{Method}

\section{Participants}

The sample (Table 1) comprised 344 first- and second-year compulsory secondary education students -169 boys $(49.13 \%)$ and 175 girls $(50.87 \%)$ - with an average age of 12.86 years (age range $12-15$ years; SD 1.121). The participants attended four public secondary schools of Zaragoza.

Participation was voluntary. All subjects and their parents/ guardians signed an informed consent form, and the ethical

Table 1 Distribution of the study sample $(N=344)$

\begin{tabular}{lllll}
\hline & First course & Second course & Total & Mean age \\
\hline Boys & 87 & 82 & 169 & 13.44 \\
Girls & 89 & 86 & 175 & 13.32 \\
Total & 176 & 168 & 344 & 13.38 \\
\hline
\end{tabular}


standards set forth in the Declaration of Helsinki, as well as all standard ethical criteria for research with human beings (the participants signed an informed consent form and were fully informed about the purpose of the study; personal data were handled with full confidentiality; no discriminatory criteria were applied; the participants faced no costs, and were given the possibility to abandon the study at any time they wished to do so).

\section{Instruments}

\section{The Eudaimonic Well-Being Questionnaire QEWB}

This instrument designed by Waterman et al. (2010) precisely reflects the philosophical representation of eudaimonia, evaluating six categories with close philosophical-psychological links: 1) Sense of control and autonomy; 2) Feeling of meaning and purpose; 3) Personal expression; 4) Feeling of belonging; 5) Social contribution and competence; and 6) Personal growth and self-acceptance. It includes 21 items divided into 7 categories with negatively worded answers. In this study, we used a 6point Likert scale (from $1=$ totally disagree to $6=$ totally agree) to avoid neutral values and to better express continuity, which is a maximum likelihood estimation assumption (Finney \& DiStefano, 2013). For the study the Spanish translation was used (Salavera \& Usán, 2019a). The reliability of the scale for this survey was $(\alpha=.82)$, which is similar to that yielded by the original scale and the Spanish translation.

\section{Emotional Intelligence Questionnaire}

This scale developed by Schutte et al. (1998) comprises 33 items. We used a 5-point Likert scale (from $1=$ totally disagree to $5=$ totally agree). The scale is supported by Salovey \& Mayer's (1990) conceptual model. Previous studies have confirmed that this instrument is a reliable tool for the study of EI based on theoretically-related constructs, group mean-scores and test-retest (Saklofske, Austin, \& Minski, 2003; Schutte et al., 1998).

The scale measures six different, but interrelated components of EI: attention to one's emotions; attention to others' emotions; regulation of emotions; expression of emotions; regulation of others' emotions; use of emotions in problem solving. For the study the Spanish translation was used (Salavera \& Usán, 2019b). The reliability of the scale for this survey was $\alpha=.83$, which is similar too to that yielded by the original scale and the Spanish translation.

\section{Positive and Negative Affect Scale for Children and Adolescents PANAS-N}

These scales developed by Watson, Clark, and Tellegen (1988) includes 20 items that describe different emotions and feelings, on two Likert scales (from $0=$ absence of emotion to $5=$ frequent occurrence of emotion). Ten items refer to positive affects (PA), which reflect feelings of activity, energy, enthusiasm, alertness and gratification. The other ten refer to negative affects (NA), which reflect feelings of anger, disgust, fear and nervousness. For the study the Spanish translation was used (Sandín, 2003). The reliability of the scale for this survey was $\alpha=0.88$ for positive affects and $\alpha=0.85$ for negative affects.

\section{Procedure}

The schools were contacted by phone to invite them to participate in the study. After handing out the questionnaires, the research aim of the survey was explained to all participants, and emphasis was laid on the importance of completing all items. In general, students had $20 \mathrm{~min}$ to respond, although a flexible approach was followed to account for the age and characteristics of participants. Participants were reminded that all the information collected would remain anonymous and confidential.

In order to ensure that all the items in the questionnaires were correctly understood, questionnaires were handed out to a small pilot group of participants $(N=51)$ prior to the survey. Questionnaires were distributed in class in the presence of the principal investigator. One inclusion criterion was the ability to read and communicate in perfect Spanish to ensure that the questionnaire was perfectly understood and completed. Exclusion criteria included incomplete questionnaires. The questionnaires were collected individually as the students finished them and reviewed to check for errors and to ensure that no questions were left unanswered. The order in which the questionnaires were handed out was counterbalanced to control possible effects of this order. Considering a sampling error of 5\% (Botella, Suero, \& Ximénez, 2012) it was concluded that the sample was representative of the province of Zaragoza (Spain).

The survey was designed as a lateral study based on natural groups, because the groups were constituted by stable independent variables, without major cultural differences. Individual differences were compared, and dependent and independent variables recorded (Ato \& Vallejo, 2015). The data were collected in October and November 2019.

\section{Data Analysis}

The data were processed with SPSS v.26.0 statistical software. After conducting normal distribution and equality of variances tests, we decided to use parametric techniques. Each variable was subject to descriptive analysis. In all cases, we used the lowest significance level possible. Bilateral tests were conducted. For two-group hypothesis testing Student's $t$-distribution was used. Average conglomerates were 
established to detect clusters and distribute participants in groups based on eudaimonic well-being, affects and EI scores. Mediation analyses were conducted to assess the effect of positive and negative affects, following Baron and Kenny's (1986) criteria. Stepwise multiple regression was used to estimate the predictive value of affects on eudaimonic well-being, following the Wald forward stepwise method.

\section{Results}

In order to analyse the results, rather than using the scores of the six dimensions of the QEWB questionnaire, following Waterman et al.'s (2010) mono-factorial method, all subscales were added to obtain an aggregate score for eudaimonic wellbeing, which was then used to establish the relationship with affects and EI.

The average scores for most factors (Table 2) are above the centre of the scale; especially high were the scores that reflect eudaimonic well-being and anxiety. Boys yielded higher scores in positive affects, whereas girls scored higher in terms of negative affects and, among EI-related factors, attention to one's own emotions, attention to others' emotions, regulation of others' emotions and the use of emotions in problem-solving. Scores by gender were compared using Cohen's $d$. Owing to the large size of the sample, Student's $t$ can erroneously detect statistically significant differences, which is the reason why Cohen's (1988) $d$ (typified average difference), which allows for the estimation of mean-difference effect size, was used. The interpretation of effect size is a simple operation: values of .20 or below indicate a small or insignificant effect size; between 0.20 and 0.49 , a small effect size; between 0.50 and 0.79 , a moderate effect size; and 0.80 or above, a large effect size (Cohen, 1988).

The correlation between eudaimonic well-being and affects and EI factors was calculated (Table 3), and shown to be statistically significant; the strongest correlations $(p \geq 0.4)$ concern attention to one's own emotions $\left(r=.483^{* *}\right)$, regulation of one's own emotions $\left(r=.595^{* *}\right)$, the use of emotions in problem-solving $\left(r=.482^{* *}\right)$, and positive $\left(r=.536^{* *}\right)$ and negative affects $\left(r=-.306^{* *}\right)$.

In addition, cluster analyses (Table 4) were conducted to divide participants into groups according to their eudaimonic well-being, affects and EI scores. Three major groups were identified: 1) 102 participants (29.65\%) with below average scores in terms of eudaimonic well-being, EI and positive affects, and above average scores in terms of negative affects; 2) 143 participants $(41.57 \%)$ with near-average scores in terms of eudaimonic well-being, EI and affects; and 3) 99 participants $(28.78 \%$ ) with above average scores in terms of eudaimonic well-being, EI and positive affects, and below average scores in terms of negative affects. In all groups, differences were found to be significant $(\mathrm{p}<0.001)$.
Figure 1 illustrates the analysis of conglomerates, outlining the profile of participants in terms of eudaimonic well-being, affects and EI by comparing individual and average scores. As the figure shows, regardless of socio-metric factors, the three constructs under consideration were shown to be positively correlated; that is, participants with high scores in terms of eudaimonic well-being also yielded high scores in terms of EI and positive affects, and lower scores in terms of negative affects. Conversely, participants with low scores in terms of eudaimonic well-being also yielded low scores in terms of EI and positive affects, and higher scores in terms of negative affects. A third group yielded near-average scores in all three constructs under consideration.

This was followed by a mediation analysis to establish the mediating effect of affects in the relationship between EI and eudaimonic well-being, as shown in Fig. 2.

This three-way interaction was investigated by 'choosing a point' using Hayes' (2013) PROCESS tool. The analysis revealed that EI has a direct effect, . $3135, p<.05$, on eudaimonic well-being $[\mathrm{F}(1,344)]=8.489 ; p<.001]$. If the mediating role of affects is taken into consideration, the effect increased to $.4800, p<001 ;[\mathrm{F}(3,344]=14.047 ; \mathrm{p}<.001]$, which proves that affects mediate the relationship between emotional intelligence and eudaimonic well-being.

Finally, in order to establish the predictive value of affects and EI over eudaimonic well-being, a hierarchical multiple regression model was implemented, using affects and EI scores as predictor variables and eudaimonic well-being as a criterion variable. Table 5 shows the steps in the models followed in the introduction of the explanatory variables that have been shown to have a significant predictive value on the likelihood of eudaimonic well-being. In the first step, the EI variables were entered into the regression model, and in the second step, the positive and negative affects. These predictive variables were, concerning EI, regulation of one's own emotions (.699), attention to one's own emotions (.376), and use of emotions in problem-solving (.510), and concerning affects, both positive (1.003) and negative affects (-.414); the Durbin-Watson test indicates that errors are independent (2.133). For the model used, these predictive variables explain $70.2 \%$ of the variance of the dependent variable $\left(R^{2}=.702\right)$.

\section{Discussion}

The aim of this study was to assess the relationship between affects, EI and eudaimonic well-being. Girls yielded higher EI-related scores (attention to both one's and others' emotions and regulation of others' emotions). This is in line with previous research (Jiménez, Esnaola, \& Saez, 2019; Joseph \& Newman, 2010; Sánchez, Fernández-Berrocal, Montañés, \& Latorre, 2008), which suggests that girls pay more attention to emotions and are better at regulating them. 
Table 2 Descriptive statistics on eudaimonic well-being, affects and emotional intelligence

\begin{tabular}{|c|c|c|c|c|c|c|c|}
\hline & \multicolumn{2}{|c|}{ Hombres } & \multicolumn{2}{|c|}{ Mujeres } & \multirow[b]{2}{*}{$t$} & \multirow[b]{2}{*}{ Sig. } & \multirow[b]{2}{*}{$d$} \\
\hline & Media & $d s$ & Media & $d s$ & & & \\
\hline Eudaimonic well-being & 79.58 & 8.10 & 80.08 & 8.96 & .051 & .959 & .005 \\
\hline Attention to your own emotions & 23.16 & 2.63 & 23.14 & 3.16 & -2.091 & .037 & -.234 \\
\hline Attention to the emotions of others & 10.14 & 2.05 & 10.77 & 1.77 & -2.463 & .014 & -.276 \\
\hline Regulation of your own emotions & 24.76 & 2.76 & 24.42 & 3.46 & -.653 & .514 & -.073 \\
\hline Expressed emotion & 14.11 & 2.73 & 14.70 & 2.35 & 1.726 & .085 & .194 \\
\hline Regulation emotions of others & 18.96 & 2.79 & 19.68 & 2.49 & -3.511 & .011 & -.390 \\
\hline Emotion in problem solving & 15.70 & 2.03 & 15.86 & 2.20 & 1.984 & .048 & .223 \\
\hline Positive affects & 18.60 & 2.57 & 18.08 & 2.74 & -2.980 & .003 & -.332 \\
\hline Negative affects & 13.00 & 3.51 & 14.26 & 3.01 & .920 & .358 & .103 \\
\hline
\end{tabular}

The results also indicate a relationship between all three constructs under consideration, also in line with existing research; it has been argued that affects play a crucial role in well-being (Diener et al., 2018), while EI has been found to have a direct impact on well-being-related traits, such as personal development and self-realisation (Bhullar et al., 2013; Di Fabio \& Kenny, 2016; Extremera, Ruiz-Aranda, PinedaGalan, \& Salguero, 2011; Schutte, Malouff, Simunek, Hollander, \& McKenley, 2002; Zeidner et al., 2012).

Cluster analyses revealed three well-defined groups: one characterised by low scores in terms of eudaimonic well-being, EI and positive affects, and high scores in negative affects; one with near average scores in all three constructs; and a third group characterised by above average scores in terms of eudaimonic well-being, EI and positive affects, and low scores in negative affects. The proportion of low scores was unexpectedly high, compared to previous studies (Luna, Rodríguez-Donaire, Rodrigo-Ruiz, \& Cejudo, 2020; Martínez-Marín \& Martínez, 2019) and especially considering that we were working with a school sample, not a clinical sample, and this should be examined further in the future.

The model used to analyse these three constructs reveals the mediating role of affects in the relationship between EI and eudaimonic well-being; affects were found to increase the effect of EI on eudaimonic well-being, that is, EI and affects have a positive effect on eudaimonic well-being. The effect of EI on hedonic and eudaimonic well-being has been thoroughly examined in the scientific literature. Our results agree with these previous research (Balluerka, Gosostiaga, AlonsoArbiol, \& Aritzeta, 2017; Bhullar et al., 2013; Di Fabio \& Kenny, 2016; Sánchez-Álvarez et al., 2016), which is unsurprising, given the characteristics of our sample and the important role played by development in early adolescence, during which, two important processes get underway: 1) the search for self-knowledge; and 2) growing personal autonomy. In these two processes, as well as in eudaimonic well-being, EI and affects play a vital role, which explains the link between these constructs (André \& Lelord, 2002; Soto, 2015). Adolescents are immersed in a phase in which their social skills (ability to interact effectively with others) and EI (ability to administer or self-regulate emotions) develop. In his or her search for well-being, the adolescent moves from concrete to abstract thoughts, develops advanced reasoning skills, and learns to better control his or her feelings. This contributes to his or her well-being and personal and psychosocial development, and also helps them to cope with problems (Salavera, Usán, Pérez, Chato, \& Vera, 2017); at this age, functional emotions and the development of the perception of

Table 3 Correlations on well-being, affects and emotional intelligence

\begin{tabular}{|c|c|c|c|c|c|c|c|c|}
\hline 1. Eudaimonic well-being & 1 & 2 & 3 & 4 & 5 & 6 & 7 & 8 \\
\hline 2. Attention to your own emotions & $.483 * *$ & & & & & & & \\
\hline 3. Attention to the emotions of others & $.293 * *$ & $.325 * *$ & & & & & & \\
\hline 4. Regulation of your own emotions & $.595 * *$ & $.531 * *$ & $.217 * *$ & & & & & \\
\hline 5. Expressed emotion & $.330 * *$ & $.341 * *$ & $.490 * *$ & $.382 * *$ & & & & \\
\hline 6. Regulation emotions of others & $.312 * *$ & $.276^{* *}$ & $.434 * *$ & $.375 * *$ & $.373 * *$ & & & \\
\hline 7. Emotion in problem solving & $.482 * *$ & $.534 * *$ & $.385 * *$ & $.538 * *$ & $.319 * *$ & $.452 * *$ & & \\
\hline 8. Positive affects & $.536^{* *}$ & $.382 * *$ & $.282 * *$ & $.441 * *$ & $.320^{*}$ & $.262 * *$ & $.416^{*}$ & \\
\hline 9. Negative affects & $-.306^{* *}$ & $-.181 * *$ & .033 & $-.386^{* *}$ & -.054 & $-.114 *$ & -.102 & -.044 \\
\hline
\end{tabular}

$* p<0.05 ; * * p<0.01$ 
Table 4 Cluster analysis on eudaimonic well-being, affects and emotional intelligence

\begin{tabular}{|c|c|c|c|c|c|c|c|c|c|}
\hline \multirow[b]{2}{*}{ Eudaimonic well-being } & \multicolumn{2}{|c|}{ GROUP 1} & \multicolumn{2}{|c|}{ GROUP 2} & \multicolumn{2}{|c|}{ GROUP 3} & \multicolumn{2}{|c|}{ TOTAL } & \multirow{2}{*}{$\begin{array}{l}\text { Sign. } \\
.000\end{array}$} \\
\hline & 71.92 & 7.11 & 80.22 & 5.70 & 87.68 & 6.00 & 79.90 & 8.66 & \\
\hline Attention to your own emotions & 20.82 & 2.93 & 23.15 & 1.99 & 25.54 & 2.24 & 23.15 & 2.98 & .000 \\
\hline Attention to the emotions of others & 9.36 & 1.90 & 10.52 & 1.38 & 11.81 & 1.73 & 10.55 & 1.89 & .000 \\
\hline Regulation of your own emotions & 21.23 & 3.00 & 24.98 & 1.90 & 27.31 & 1.64 & 24.54 & 3.23 & .000 \\
\hline Expressed emotion & 12.73 & 2.53 & 14.47 & 1.68 & 16.35 & 2.10 & 14.49 & 2.50 & .000 \\
\hline Regulation emotions of others & 17.57 & 2.44 & 19.40 & 1.98 & 21.37 & 2.21 & 19.43 & 2.62 & .000 \\
\hline Emotion in problem solving & 13.79 & 1.79 & 15.91 & 1.35 & 17.72 & 1.50 & 15.80 & 2.14 & .000 \\
\hline Positive affects & 16.24 & 2.32 & 18.30 & 2.25 & 20.29 & 2.02 & 18.26 & 2.69 & .000 \\
\hline Negative affects & 14.96 & 3.45 & 13.82 & 2.85 & 12.64 & 3.18 & 13.82 & 3.25 & .000 \\
\hline $\mathrm{N}$ & \multicolumn{2}{|l|}{102} & \multicolumn{2}{|l|}{143} & \multicolumn{4}{|l|}{99} & \\
\hline (\% total) & \multicolumn{2}{|c|}{$(29.65 \%)$} & \multicolumn{2}{|c|}{$(41.57 \%)$} & \multicolumn{2}{|c|}{$(28.78 \%)$} & & & \\
\hline
\end{tabular}

eudaimonic well-being, which is among the individual's goals (Waterman, 2008) has to do with the adolescent's prospects and expectations for the future.

Concerning the predictive value of affects and EI over eudaimonic well-being, it was found that predictor factors were, in relation to EI, regulation of one's own emotions, attention to one's own emotions, and use of emotions in problem solving, and in relation to affects, both positive and negative (both of which were shown to have a significant effect on eudaimonic well-being). Negative affects were found to be negatively correlated with eudaimonic well-being. This suggests that factors most closely related with the person (attention to and regulation of one's own emotions, and the use of emotions in problem-solving) are useful tools for the prediction of eudaimonic well-being; that is, EI (which in the study was measured as a trait) to a large extent determines eudaimonic well-being and, therefore, a sense of meaning of life and self-realisation (Di Fabio \& Kenny, 2016; Ryan, Huta, \& Deci, 2008; Ryff, 1989). This can be explained from a eudaimonic perspective; psychological well-being stems from personal development and self-realisation, the alignment of targets and self, a relationship in which EI plays a major role (Ryff \& Singer, 2008; Zeidner et al., 2012).

\section{The Limitations of this Study}

This study has some important limitations. Although the sample is large, more longitudinal studies, which take into consideration other age groups, need to be undertaken. In addition, positive psychology often comes under fire for focusing its research on the developed western world (Selin \& Davey, 2012), and this should be redressed. Similarly, the constructs analysed in this study should be put in relation with other constructs, such as hedonic well-being, happiness, life
Fig. 1 Participant groups grouped by eudaimonic well-being, affects and emotional intelligence

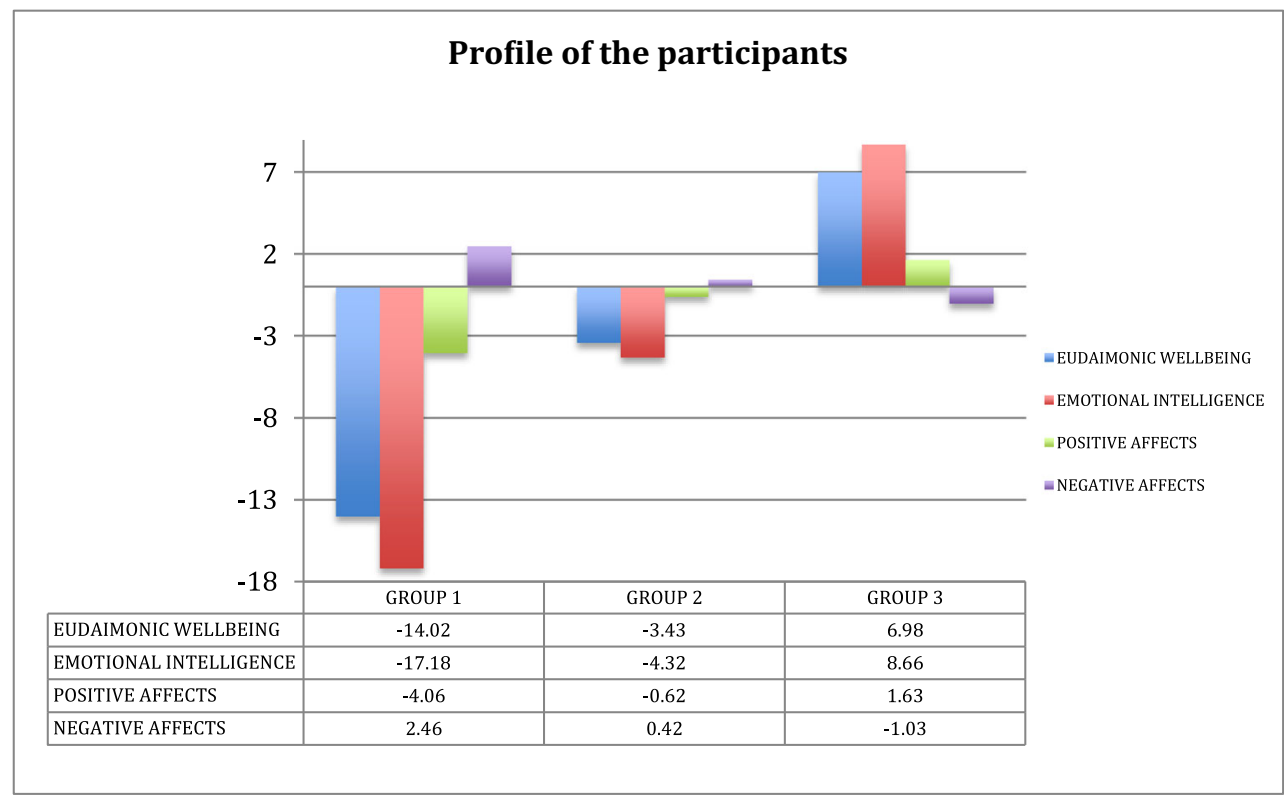




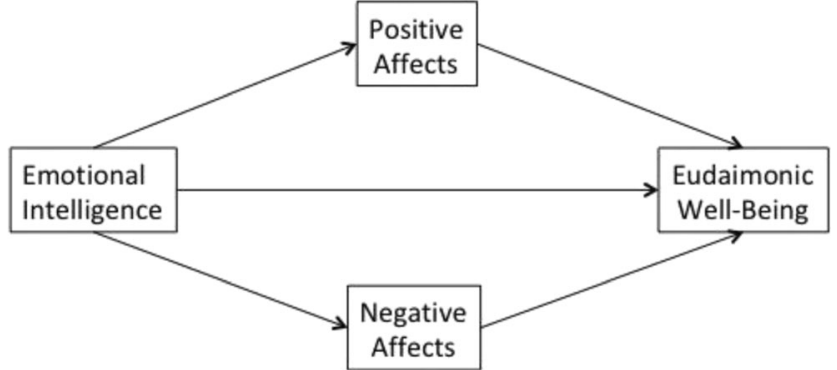

Fig. 2 Hypothetic model of the relationship between emotional intelligence, affects, and eudaimonic well-being

satisfaction and self-esteem. It could also be said that the limitations of this study lie in its cross-sectional design since data were collected at a given moment in time. The scores can change from one year to the next and even with in the same school year, depending on the students' personal and contextual circumstances.

\section{Conclusions}

Although much work remains to be done, our results provide valuable evidence for the relationship between eudaimonic well-being, affects and EI; these conclusions have practical implications, in the development of educational programmes that specifically target these constructs at the school level, contributing to improve eudaimonic well-being, EI and affects in adolescents, which in turn will help them in their personal, social and emotional performance. Finally, it is worth stressing that our results are but one step which encourages us to continue our research and develop new methodologies with the ultimate aim of contributing to the socio-emotional development of adolescents.

The main conclusion of this study is that eudaimonic wellbeing, EI and affects are correlated, which helps us to better understand and measure these constructs in adolescents; this can be used by teachers and parents to detect deficits in wellbeing, EI and affects, and design educational measures accordingly. Well-being, EI and affects have enormous implications for the life of adolescents, and they should be regarded as a priority for all those who work with them.

\section{Future Prospects}

In the future, it would be fruitful to implement longitudinal models to evaluate the evolution of the constructs under analysis over time. This, however, poses the additional logistical challenge of tracing each subject over several periods. It would also be interesting to take into consideration other educational tiers, such as primary schools and universities. Similarly, the constructs analyzed in this study should be related to other constructs, such as hedonic well-being, happiness, life satisfaction and self-esteem or other important factors that can affect eudaimonic well-being in adolescents, such

Table 5 Affects and emotional intelligence as predictors of eudaimonic well-being

\begin{tabular}{|c|c|c|c|c|c|c|}
\hline & & $B$ & e.t. & $R^{2}$ & $t$ & Sig \\
\hline \multirow[t]{2}{*}{ Step 1} & (Constant) & 40.770 & 2.881 & .595 & 14.154 & .000 \\
\hline & Regulation of your own emotions & 1.595 & .116 & & 13.704 & .000 \\
\hline \multirow[t]{3}{*}{ Step 2} & (Constant) & 33.264 & 3.227 & .627 & 10.307 & .000 \\
\hline & Regulation of your own emotions & 1.264 & .133 & & 9.480 & .000 \\
\hline & Attention to one's own emotions & .674 & .145 & & 4.661 & .000 \\
\hline \multirow[t]{4}{*}{ Step 3} & (Constant) & 30.414 & 3.312 & .641 & 9.183 & .000 \\
\hline & Regulation of your own emotions & 1.107 & .141 & & 7.863 & .000 \\
\hline & Attention to one's own emotions & .507 & .152 & & 3.328 & .001 \\
\hline & Use of emotions in problem-solving & .670 & .212 & & 3.152 & .000 \\
\hline \multirow[t]{5}{*}{ Step 4} & (Constant) & 24.710 & 3.258 & .688 & 7.584 & .000 \\
\hline & Regulation of your own emotions & .905 & .137 & & 6.607 & .000 \\
\hline & Attention to one's own emotions & .393 & .145 & & 2.709 & .007 \\
\hline & Use of emotions in problem-solving & .430 & .204 & & 2.104 & .036 \\
\hline & Positive affects & .935 & .146 & & 6.386 & .000 \\
\hline \multirow[t]{6}{*}{ Step 5} & (Constant) & 33.372 & 3.991 & .702 & 8.362 & .000 \\
\hline & Regulation of your own emotions & .699 & .146 & & 4.793 & .000 \\
\hline & Attention to one's own emotions & .376 & .143 & & 2.631 & .009 \\
\hline & Use of emotions in problem-solving & .510 & .202 & & 2.525 & .012 \\
\hline & Positive affects & 1.003 & .145 & & 6.915 & .000 \\
\hline & Negative affects & -.414 & .114 & & -3.635 & .000 \\
\hline
\end{tabular}

Excluded variables: Attention to the emotions of others; Expressed emotion; Regulation emotions of others 
as social skills, school performance and family environment, which were not taken into consideration, but should be incorporated in future studies. Likewise, it would be interesting to consider other related variables, such as sociodemographic characteristics, such as gender, school year, type of school, and other social and personal variables such as socioeconomic level.

Author Contributions Conceptualization, C.S. and P.U.; methodology, C.S. and P.U.; validation, C.S. and P.U.; formal analysis, C.S. and P.U.; investigation, C.S. and P.U.; resources, C.S. and P.U.; data curation, C.S. and P.U.; writing - original draft preparation, C.S. and P.U.; writing - review and editing, C.S. and P.U.; funding acquisition, C.S. All authors have read and agreed to the published version of the manuscript.

Funding This study was performed by Research Group OPIICS (S46 20R), University of Zaragoza (Zaragoza, Spain) and was supported by research funds provided by the Department of Science and Technology of the Government of Aragón (Spain) and the European Social Fund.

Data Availability The datasets generated during and/or analysed during the current study are available from the corresponding author on reasonable request.

\section{Compliance with Ethical Standards}

Conflict of Interest The authors declare no conflict of interest. The funders had no role in the design of the study; in the collection, analyses, or interpretation of data; in the writing of the manuscript, or in the decision to publish the results.

\section{References}

André, C., \& Lelord, F. (2002). La fuerza de las emociones. Barcelona: Kairós.

Ato, M., \& Vallejo, G. (2015). Diseños de investigación en Psicología. Madrid: Pirámide.

Balluerka, N., Gosostiaga, A., Alonso-Arbiol, I., \& Aritzeta, A. (2017). Peer attachment and class emotional intelligence as predictors of adolescents' psychological well-being: A multilevel approach. Journal of Adolescence, 53, 1-9. https://doi.org/10.1016/j. adolescence.2016.08.009.

Baron, R. M., \& Kenny, D. A. (1986). The moderator-mediator variable distinction in social psychological research: Conceptual, strategic and statistical considerations. Journal of Personality and Social Psychology, 51, 1173-1182. https://doi.org/10.1037/0022-3514. 51.6.1173.

Besser, L. L. (2016). Conceptual challenges for a science of eudaimonic well-being. In J. Vittersø (Ed.), Handbook of eudaimonic well-being (pp. 85-91). Cham, Switzerland: Springer.

Bhullar, N., Schutte, N. S., \& Malouff, J. M. (2013). The nature of wellbeing: The roles of hedonic and Eudaimonic processes and trait emotional intelligence. Journal of Psychology, 147(1), 1-16. https://doi.org/10.1080/00223980.2012.667016.

Botella, J., Suero, M., \& Ximénez, C. (2012). Análisis de datos en Psicología I. Madrid: Pirámide.

Cabello, R., \& Fernández-Berrocal, P. (2015). Implicit theories and ability emotional intelligence. Frontiers in Psychology, 6(700), 1-8. https://doi.org/10.3389/fpsyg.2015.00700.
Canero, M., Monaco, E., \& Montoya, I. (2019). Emotional intelligence and empathy as predictors of subjective well-being in universitary students. European Journal of Investigation in Health Psychology and Education, 9(1), 19-29. https://doi.org/10.30552/ejihpe.v9i1. 313.

Church, A. T., Katigbak, M. S., Mazuera, R., Rincon, B. C., VargasFlores, J.d. J., Ibáñez-Reyes, J., Wang, L., Alvarez, J. M., Wang, C., \& Ortiz, F. A. (2014). A four-culture study of self-enhancement and adjustment using the social relations model: Do alternative conceptualizations and indices make a difference? Journal of Personality and Social Psychology, 106(6), 997-1014. https://doi. org/10.1037/a0036491.

Cohen, J. (1988). Statistical power analysis for the behavioral sciences (2nd ed.). Hillsdale, NJ: Erlbaum.

Cooke, P. J., Melchert, T. P., \& Connor, K. (2016). Measuring wellbeing: A review of instruments. The Counseling Psychologist, 44, 730-757. https://doi.org/10.1177/0011000016633507.

Di Fabio, A., \& Kenny, M. E. (2016). Promoting well-being: The contribution of emotional intelligence. Frontiers in Psychology, 7, 1182. https://doi.org/10.3389/fpsyg.2016.01182.

Di Fabio, A., \& Saklofske, D. H. (2018). The contributions of personality and emotional intelligence to resiliency. Personality and Individual Differences, 123, 140-144. https://doi.org/10.1016/j.paid.2017.11. 012.

Diener, E., Lucas, R. E., \& Oishi, S. (2018). Advances and open questions in the science of subjective well-being. Collabra: Psychology, 4(1), 1-78. https://doi.org/10.1525/collabra.115.

Extremera, N., Ruiz-Aranda, D., Pineda-Galan, C., \& Salguero, J. M. (2011). Emotional intelligence and its relation with hedonic and eudaimonic well-being: A prospective study. Personality and Individual Differences, 51(1), 11-16. https://doi.org/10.1016/j. paid.2011.02.029.

Fernández-Berrocal, P. \& Extremera, N. (2005). La inteligencia emocional y la educación de las emociones desde el modelo de Mayer y Salovey. Revista Interuniversitaria de Formación del Profesorado, 19(3), 63-93.

Finney, S. J., \& DiStefano, C. (2013). Nonnormal and categorical data in structural equation modeling. In G. R. Hancock \& R. O. Mueller (Eds.), Quantitative methods in education and the behavioral sciences: Issues, research, and teaching. Structural equation modeling: A second course (p. 439-492). IAP Information Age Publishing.

Hayes, A.F. (2013). Methodology in the social sciences.Introduction to mediation, moderation, and conditional process analysis: A regression-based approach. Guilford Press.

Huta, V., \& Waterman, A. S. (2014). Eudaimonia and its distinction from hedonia: Developing a classification and terminology for understanding conceptual and operational definitions. Journal of Happiness Studies, 15, 1425-1456. https://doi.org/10.1007/ s10902-013-9485-0.

Jiménez, M. N., Esnaola, I., \& Saez, I. A. (2019). Emotional intelligence predictive variable subjective well-being in adolescence. Revista Interuniversitaria de Formación del Profesorado, 94, 127-144.

Joseph, D. L., \& Newman, D. A. (2010). Emotional intelligence: An integrative meta-analysis and cascading model. Journal of Applied Psychology, 95(1), 54-78.

Kahneman, D., Diener, E., \& Schwarz, N. (1999). Well-being: The foundations of hedonic psychology. New York: Sage. Marsh, H. W., Hau, K. T., \& wen, Z. (2004). In search of golden rules: Comment on hypothesis-testing approaches to setting cutoff values for fit indexes and dangers in overgeneralizing Hu and Bentler's (1999) findings. Structural Equation Modeling, 11, 320-341.

Karaś, D., \& Cieciuch, J. (2018). The relationship between identity processes and well-being in various life domains. Personality and Individual Differences, 121, 111-119. https://doi.org/10.1016/j. paid.2017.09.027. 
Luna, P., Rodríguez-Donaire, A., Rodrigo-Ruiz, D., \& Cejudo, J. (2020). Subjective well-being and psychosocial adjustment: Examining the effects of an intervention based on the sport education model on children. Sustainability, 12(11), 4570. https://doi.org/10.3390/ su12114570.

Martínez-Marín, M. D., \& Martínez, C. (2019). Subjective well-being and gender-typed attributes in adolescents: The relevance of emotional intelligence. Australian Journal of Psychology, 71(3), 296304. https://doi.org/10.1111/ajpy.12247.

Mayer, J. D., Caruso, D. R., \& Salovey, P. (2016). The ability model of emotional intelligence: Principles and updates. Emotion Review, 8(4), 290-300. https://doi.org/10.1177/1754073916639667.

Mayer, J. D., Salovey, P., \& Caruso, D. R. (2008). Emotional intelligence: New ability or eclectic traits? American Psychologist, 63(6), 503-517. https://doi.org/10.1037/0003-066X.63.6.503 https://psycnet.apa.org/doi/10.1037/0003-066X.63.6.503.

Mayer, J. D., Salovey, P., Caruso, D. R., \& Cherkasskiy, L. (2011). Emotional intelligence. In R. J. Sternberg \& S. B. Kaufman (Eds.), Cambridge handbooks in psychology. The Cambridge handbook of intelligence ( $p$. 528-549). Cambridge University Press. https://doi. org/10.1017/CBO9780511977244.027.

Petrides, K. V. (2016). Four thoughts on trait emotional intelligence. Emotion Review, 8(4), 345. https://doi.org/10.1177/ 1754073916650504.

Ryan, R. M., \& Deci, E. L. (2001). On happiness and human potentials: A review of research on hedonic and eudaimonic well-being. Annual Review of Psychology, 52, 141-166.

Ryan, R. M., Huta, V., \& Deci, E. L. (2008). Living well: A selfdetermination theory perspective on eudaimonia. Journal of Happiness Studies, 9, 139-170.

Ryff, C. D. (1989). Happiness is everything, or is it? Explorations on the meaning of psychological well-being. Journal of Personality and Social Psychology, 57, 1069-1081. https://doi.org/10.1037/0022351457.6.1069.

Ryff, C. D., \& Singer, B. H. (2008). Know thyself and become what you are: A eudaimonic approach to psychological well-being. Journal of Happiness Studies, 9(1), 13-39. https://doi.org/10.1007/s10902006-9019-0.

Saklofske, D. H., Austin, E. J., \& Minski, P. S. (2003). Factor structure and validity of a trait emotional intelligence measure. Personality and Individual Differences, 34(4), 707-721. https://doi.org/10. 1016/S0191-8869(02)00056-9.

Salavera, C., \& Usán, P. (2019a). Propiedades psicométricas del cuestionarios QEWB de bienestar eudaimónico en adolescentes. Psicología Educativa, 25, 139-146. https://doi.org/10.5093/ psed2019a3.

Salavera, C., \& Usán, P. (2019b). Exploración de la dimensionalidad y las propiedades psicométricas de la escala EIS de inteligencia emocional. CES Psicología, 12(3), 50-66. https://doi.org/10. 21615/cesp.12.3.4.

Salavera, C., Usán, P., Pérez, S., Chato, A., \& Vera, R. (2017). Differences in happiness and coping with stress in secondary education students. Procedia-Social and Behavioral Sciences, 237, 1310e1315-1310e1315. https://doi.org/10.1016/j.sbspro.2017.02. 215.

Salovey, P. \& Mayer, J.D. (1990). "Emotional intelligence”. Imagination, Cognition, and Personality, 9, 185-211.

Sánchez, M. T., Fernández-Berrocal, P., Montañés, R., \& Latorre, J. M. (2008). ¿Es la inteligencia emocional una cuestión de género? Socialización de las competencias emocionales en hombres y mujeres y sus implicaciones. Revista Electrónica de Investigación Psicoeducativa, 15(2), 455-474.
Sánchez-Álvarez, N., Extremera, N., \& Fernández-Berrocal, P. (2016). The relation between emotional intelligence and subjective wellbeing: A metaanalytic investigation. The Journal of Positive Psychology, 11(3), 276-285. https://doi.org/10.1080/17439760. 2015.1058968

Sandín, B. (2003). Escalas PANAS de afecto positivo y negativo Para niños y adolescentes (PANASN). Revista de Psicopatología y Psicología Clínica, 8(2), 173-182.

Schutte, N. S., Malouff, J. M., Hall, L. E., Haggerty, D. J., Cooper, J. T., Golden, C. J., \& Dornheim, L. (1998). Development and validation of a measure of emotional intelligence. Personality and Individual Differences, 25, 167-177.

Schutte, N. S., Malouff, J. M., Simunek, M., Hollander, S., \& McKenley, J. (2002). Characteristic emotional intelligence and emotional wellbeing. Cognition and Emotion, 16, 769-785.

Seligman, M. E. P., \& Csikszentmihalyi, M. (2000). Positive psychologyan introduction. American Psychologist, 55, 5-14.

Selin, H., \& Davey, G. (2012). Introduction. In H. Selin \& G. Davey (Eds.), Happiness across cultures: Views of happiness and quality of life in non-Western cultures (pp. 1-12). New York, NY: Springer. https://doi.org/10.1007/978-94-007-2700-7_1.

Soto, C. J. (2015). Is happiness good for your personality? Concurrent and prospective relations of the big five with subjective well-being. Journal of Personality, 83, 45-55. https://doi.org/10.1111/jopy. 12081.

Tamir, M., Vishkin, A., \& Gutentag, T. (2020). Emotion regulation is motivated. Emotion, 20(1), 115-119. https://doi.org/10.1037/ emo0000635.

Waterman, A. S. (1993). Two conceptions of happiness: Contrasts of personal expressiveness (eudaimonia) and hedonic enjoyment. Journal of Personality and Social Psychology, 64(4), 678-691. https://doi.org/10.1037/0022-3514.64.4.678.

Waterman, A. S. (2008). Reconsidering happiness: A eudaimonist's perspective. The Journal of Positive Psychology, 3, 234-252. https:// doi.org/10.1080/17439760802303002.

Waterman, A.S. (2011). Eudaimonic identity theory: Identity as self-discovery. In S. J. Schwartz, K. Luyckx, \& V. L. Vignoles (Eds.), Handbook of identity theory and research. Vol. 1, 2. New York, NY: Springer.

Waterman, A.S., Schwartz, S.J., Zamboanga, B.L., Ravert, R.D., Williams, M.K., Agocha, V.B., ...., \& Donnellan, M.B. (2010). The questionnaire for Eudaimonic well-being: Psychometric properties, demographic comparisons, and evidence of validity. The Journal of Positive Psychology, 5(1), 41-61. https://doi.org/10. 1080/17439760903435208.

Watson, D., Clark, L. A., \& Tellegen, A. (1988). Development and validation of brief measures of positive and negative affect: The PANAS scales. Journal of Personality and Social Psychology, 54(6), 1063-1070.

Zeidner, M., Matthews, G., \& Roberts, R. D. (2012). The emotional intelligence, health, and well-being nexus: What have we learned and what have we missed? Applied Psychology Health Well-Being, 4, 1-30. https://doi.org/10.1111/j.1758-0854.2011.01062.x.

Zhoc, K. C. H., Li, J. C. H., \& Webster, B. J. (2016). New reliability and validity evidence of the emotional intelligence scale. Journal of Psychoeducational Assessment, 1, 16-614. https://doi.org/10.1177/ 0734282916653901.

Publisher's Note Springer Nature remains neutral with regard to jurisdictional claims in published maps and institutional affiliations. 